\title{
CULTURA E DANÇAS REGIONAIS EM UM PROJETO PEDAGÓGICO DE UMA PROFESSORA DE EDUCAÇÃO FÍSICA
}

\author{
Marcos Godoi \\ Rede Municipal de Educação de Cuiabá, Cuiabá, Mato Grosso, Brasil \\ Beleni Salete Grando \\ Universidade Federal de Mato Grosso, Cuiabá, Mato Grosso, Brasil \\ Gutemberg Santana Xavier \\ Rede Paeticular de Educação de Cuiabá, Cuiabá, Mato Grosso, Brasil
}

\begin{abstract}
Resumo
O objetivo deste estudo foi compreender o ensino da cultura e das danças regionais em um projeto pedagógico de uma professora de educação física. Para isto, foi realizado um estudo de caso com uma professora experiente, que atua em uma escola municipal de Cuiabá-MT, Brasil. Os instrumentos e procedimentos de coleta de dados foram um formulário, uma entrevista semiestruturada e consulta de documentos (memorial, relatório do projeto, fotos). As danças presentes neste projeto pedagógico foram: siriri, cururu, rasqueado, chorado e dança dos mascarados. Além disto, a professora utiliza várias estratégias pedagógicas, trabalha de forma interdisciplinar e vinculada ao Projeto Político Pedagógico da escola, e sua prática baseia-se na pedagogia crítico-superadora e no multiculturalismo.
\end{abstract}

Palavras-chave: Cultura. Dança. Ensino. Professores escolares.

\section{CULTURE AND REGIONAL DANCES IN A PEDAGOGICAL PROJECT OF A PHYSICAL EDUCATION TEACHER}

\begin{abstract}
The goal of this study was to understand the teaching of culture and regional dances in a pedagogical project of a physical education teacher. For this, a case study was carried out with an experienced teacher, who works in a municipal school in Cuiabá-MT, Brazil. The instruments and procedures for data collection were a form, a semi-structured interview and consultation of documents (memorial, project report, photos). The dances present in this pedagogical project were: siriri, cururu, rasqueado, chorado and mascarados dance. In addition, the teacher uses several pedagogical strategies, works in an interdisciplinary way, it is linked to the school's Political Pedagogical Project and its pedagogical practice is based on critical pedagogy and multiculturalism.
\end{abstract}

Keywords: Culture. Dancing. Teaching. School teachers. 


\section{CULTURA Y DANZAS REGIONALES EN UN PROYECTO PEDAGÓGICO DE UNA PROFESORA DE EDUCACIÓN FÍSICA}

\section{Resumen}

El objetivo de este estudio fue comprender la enseñanza de la cultura y las danzas regionales en un proyecto pedagógico de una maestra de educación física. Para ello, se realizó un estudio de caso con una maestra experimentada, que actúa en una escuela municipal de Cuiabá-MT, Brasil. Los instrumentos y procedimientos de recolección de datos fueron un formulario, una entrevista semiestructurada y consulta de documentos (memorial, informe del proyecto, fotos). Las danzas presentes en este proyecto pedagógico fueron: siriri, cururu, rasqueado, llorado y danza de los enmascarados. Además de eso, la profesora utiliza varias estrategias pedagógicas, trabaja de forma interdisciplinaria y vinculada al Proyecto Político Pedagógico de la escuela, y su práctica se basa en la pedagogía crítico-superadora y en el multiculturalismo.

Palabras clave: cultura. danzas. enseñanza. maestros.

\section{Introdução}

O ensino das danças na escola já foi abordado nas pesquisas sob diferentes perspectivas, seja analisando a inserção ou não deste componente no currículo da educação física (BRASILEIRO, 2002, 2008; SBÓRQUIA; NEIRA, 2008; BUOGO; LARA, 2011; SOUZA; HUNGER; CARAMASCHI; 2014; ALVES et al., 2015); o ensino da dança em projetos extracurriculares (STRAZZACAPPA, 2003; MARQUES; SURDI; KUNZ, 2013); seja investigando as percepções dos professores do Ensino Fundamental sobre o ensino da dança (KLEINUBING; SARAIVA, 2009) ou os motivos da prática das danças de salão pelos alunos nas aulas de educação física (SHIBUKAWA et al., 2011); a dança e os estereótipos de gênero e de movimento no Ensino Médio (KLEINUBING; SARAIVA; FRANCISQUINI, 2013); a inserção da dança na escola em seus diferentes tempos e espaços (FIGUEIREDO, 2013); ou o uso de um blog como instrumento para o ensino das danças folclóricas (DINIZ; DARIDO, 2015).

Ainda que estas investigações tenham lançado luz sobre questões importantes para o ensino da dança no contexto escolar, são escassas as pesquisas que investigam experiências e projetos pedagógicos extracurriculares de dança na escola. Deste modo, esta pesquisa se interessa pelo trabalho pedagógico de uma professora de educação física (EF), que se destaca na Rede Municipal de Educação de Cuiabá-MT, por ela desenvolver um projeto extracurricular sobre a cultura e as danças mato-grossenses.

Sobre os projetos pedagógicos que abordam as danças na escola, Figueiredo (2013) defende a realização de trabalhos e projetos integrados e transdisciplinares que iniciem dialogando com a realidade social e cultural, valorizando as produções artísticas regionais, mas que experimentem novas relações culturais a partir das experiências com o corpo e o movimento, entendendo que o corpo é um fenômeno histórico, cultural e artístico. Além disso, a dança deve ser considerada um elemento integrador e mediador dos diferentes saberes, não sendo apenas uma expressão teórica, prática ou técnica, mas que possibilite trabalhos transdisciplinares.

Por sua vez, Strazzacappa (2003) destaca que geralmente a dança está presente no contexto escolar como atividade extracurricular, tratando-se de projetos isolados, frutos de iniciativa pessoal de um professor da escola ou de um aluno (bailarino ou que estuda dança em cursos livres) que tem a iniciativa de criar um grupo de dança na escola. Analisando os projetos de dança realizados nas escolas de Campinas-SP, a pesquisadora constatou que alguns projetos têm uma visão assistencialista e são pouco estruturados, outros reproduzem de forma acrí- 
tica os modismos televisivos. Por outro lado, há também projetos com uma preocupação educativa mais acentuada e que fogem do simples assistencialismo. Segundo a autora, o sucesso destes projetos se deve justamente ao diálogo com a comunidade, sendo que o proponente ouve os anseios e interesses da comunidade e os incorpora na proposta do projeto.

Com base nestas considerações, o objetivo desta pesquisa foi compreender o ensino da cultura e das danças regionais mato-grossenses em um projeto pedagógico denominado "Beleza tem raízes", bem como identificar a história de vida, de formação e de atuação profissional da professora responsável por desenvolver este projeto. Para isto, realizamos um estudo de caso, sendo que a escolha se deu por sua representatividade tipológica, ou seja, por esta professora se destacar na rede municipal por desenvolver um trabalho com a cultura e danças matogrossenses. Vale destacar, ainda, que esta professora ganhou um prêmio nacional de projetos pedagógicos e que ela organiza anualmente o Encontro Interescolar de Dança e Cultura da Cidade Educadora (EIDANCCE), com o apoio dos profissionais da sua escola e de parceiros externos.

Devido ao caráter público do seu trabalho, que extrapolou os muros da escola, o anonimato da professora seria praticamente impossível. Por isso, pedimos sua autorização para a publicação de seu verdadeiro nome e da escola em que trabalha, o que foi concedido. Assim, este estudo de caso foi realizado com a professora Sueli Fátima Xavier Ribeiro, que tem 30 anos de experiência profissional e atua na escola municipal Marechal Rondon, em Cuiabá-MT e leciona para alunos do Ensino Fundamental.

Segundo Alves-Mazzotti (2006), os estudos de casos mais comuns são os que investigam apenas uma unidade ou instância específica, como: um indivíduo, um pequeno grupo, uma instituição, um programa. Porém, existem também os estudos de casos múltiplos, nos quais vários indivíduos ou instituições são estudadas ao mesmo tempo. Para Stake (2000 apud ALVES-MAZZOTTI, 2006), o estudo de caso é uma estratégia de pesquisa e sua característica principal é justamente esse interesse por casos específicos. Além disso, um estudo de caso pode fazer uso de diferentes métodos de pesquisa, tanto quantitativos, quanto qualitativos. De acordo com este autor, um caso é uma unidade específica, um sistema cujas partes são interligadas. Corroborando esta ideia, André (1984) destaca que o estudo de caso não é um método particular de estudo, mas uma forma particular de estudo. Ele tem um valor único, próprio e singular. Sua metodologia é eclética, envolvendo, via de regra, observação, entrevistas, fotografias, gravações, anotações de campo e negociações com os participantes (ANDRÉ, 1984).

Entre as diferentes modalidades de estudos de caso, Bogdan e Biklen (1994) citam os estudos de caso numa perspectiva histórica e as histórias de vida. Deste modo, acrescentamos que esta pesquisa se inscreve também nos estudos de histórias de vida de professores (NÓVOA, 1995), pois tentamos reconstruir a carreira da professora participante do estudo, desde suas formações pré-profissional e profissional, passando pelos pressupostos metodológicos utilizados, até chegar no projeto pedagógico e nos sub-projetos anuais desenvolvidos por ela.

Vale notar que não é possível fazer generalizações a partir do estudo de um único caso, que é singular. Porém, Stake (2000) elaborou a noção de "generalização naturalística" como alternativa à generalização baseada em amostras consideradas representativas de uma população. A generalização naturalística consiste na descrição da narrativa do caso de uma forma densa e viva, o que permite ao leitor uma experiência vicária, ou seja, leva-os a associarem o que foi observado e narrado naquele caso a acontecimentos vividos por eles em outros contextos, permitindo assim a comparação a outras situações (ALVES-MAZZOTTI, 2006).

A professora participante assinou o termo de consentimento livre e esclarecido e nós realizamos a coleta de dados. Foi utilizado um formulário com questões sobre a formação e atuação profissional e um roteiro de entrevista semiestruturada. Neste último, as questões versavam sobre a história de vida e a formação, o trabalho pedagógico e os projetos desenvolvi- 
dos. Além disto, a professora nos concedeu alguns documentos para consulta: o memorial descritivo de sua formação e atuação profissional, o relatório do projeto "Beleza tem raízes", fotografias e vídeos. Estas informações nos permitiram investigar o projeto pedagógico desenvolvido ao longo de três anos (2009, 2010 e 2011). Algumas fotos do acervo pessoal da professora serão apresentadas com a sua permissão. Nós escolhemos fotos nas quais a distância não permite uma identificação nítida dos fotografados. Para validar as informações, nós consultamos duas assessoras pedagógicas da Secretaria Municipal de Educação, uma delas era assessora na escola da professora e a outra já lecionou nesta escola, e conhece bem o trabalho pedagógico da participante do estudo.

No que se refere à interpretação das informações coletadas, nós agrupamos em unidades de análise, a saber: história de vida e de formação profissional; princípios metodológicos da prática com a dança e projetos pedagógicos interdisciplinares. Nosso referencial teórico para a análise baseia-se na pedagogia crítico-superadora e no multiculturalismo. De início, vale notar que a abordagem pedagógica crítico-superadora na $\mathrm{EF}$, de inspiração marxista, própria de uma concepção crítica de educação, trata os conhecimentos historicamente construídos como parte da cultura corporal humana. Estes conhecimentos são sistematizados e pedagogizados para desenvolver nos alunos uma compreensão crítica da realidade social. Segundo McLaren (2001), tanto o multiculturalismo crítico quanto a pedagogia crítica buscam contestar vigorosamente a persistência de desigualdades de raça, gênero e classe, seja essa desigualdade baseada na posse da propriedade, na persistência do patriarcado ou na homofobia.

\section{Apresentação e discussão dos resultados}

Nesta sessão, nós apresentaremos e discutiremos as informações coletadas no estudo de caso, começando pela história de vida e de formação profissional da professora.

\section{História de vida e de formação profissional}

Segundo as informações consultadas, a professora Sueli nasceu em Lins-SP, no dia 27 de outubro de 1958. Quando criança, ela gostava de ir ao circo com seus irmãos para ver as acrobacias dos trapezistas. Aos seis anos ela ficou órfã de pai, que era dedicado à família e foi um bom jogador de futebol, influenciando o seu gosto pelo esporte. Ela sempre foi empenhada nas práticas esportivas, como corridas, salto em distância e voleibol, mas não pode se dedicar muito em função do trabalho.

Sueli ingressou na faculdade de EF aos 24 anos de idade. Ela ganhou uma bolsa de estudos parcial para representar a faculdade como atleta. Além disto, ela relatou que, neste período, participava de encontros musicais nos saraus da cidade e que gostava de ouvir as bandas marciais e as orquestras. Em 1987, ela se formou, mas devido à dificuldade para conseguir trabalho em sua cidade natal, ela imigrou para Cuiabá e logo começou a trabalhar em escolas e academias.

No ano de 1999 a professora foi aprovada no concurso público para atuar nas escolas municipais de Cuiabá. Em 2003, ela conseguiu a ampliação do seu vínculo de trabalho de 20 horas para 40 horas semanais. Desde então, ela trabalha somente em uma escola e leciona para 16 turmas, do $1^{\circ}$ ao $6^{\circ}$ ano do Ensino Fundamental, aspecto que permite um maior envolvimento em um único local de trabalho.

Sueli Ribeiro relatou na entrevista que na sua infância e adolescência (formação préprofissional), ela não teve vivência com a dança, nem na escola, nem fora dela. Na faculdade (formação profissional) o currículo era mais técnico/esportivo e ela também não teve muito contato com a dança. Conforme I. Betti e M. Betti (1996), um grande número de professores de EF teve como modelo de formação o currículo tradicional-esportivo, que enfatiza as disci- 
plinas "práticas", especialmente as esportivas, nas quais o graduando deveria executar e demonstrar suas habilidades técnicas e capacidades físicas.

A professora participou de um curso de especialização em EF escolar. Neste, ela teve a oportunidade de aperfeiçoar a sua prática pedagógica e começou a entender como trabalhar com a dança na escola. Ela destacou a influência da abordagem crítico-superadora nesta formação e em sua prática:

(...) E muitas pessoas até hoje se baseiam, como eu, eu não só me baseio no livro Coletivo de Autores, mas em outros também, como Vygostsky, e tem outros que eu vou buscando, como alguns específicos de dança e da cultura afro. Mas a base do meu trabalho ainda é o Coletivo de Autores, onde você busca, você valoriza o que a criança tem, o que ela traz pra você, dentro da proposta da EF e dentro da proposta da escola (RIBEIRO, 2012a).

Esta especialização e a fundamentação teórica com livros da EF, dança e cultura afro contribuíram para constituir os saberes da professora, mas não só isto, a vida cultural dela também influenciou seu trabalho pedagógico. Ela relatou que costuma assistir a filmes sobre questões raciais, dança, culturas e religiões de diferentes povos, e ainda:

Me relaciono com artista local, regional, frequento festas religiosas, lançamento de livro, teatro infantil, enfim procuro respirar cultura em todos os momentos que posso, não desperdiço meu tempo com programas que não contribui com a minha proposta de vida. Considero que essa consciência é fator primordial para enriquecer a minha prática pedagógica (RIBEIRO, 2012a).

Além disto, a professora é aberta à experimentação de outras linguagens em sua prática:

(...) eu fiz uma mostra de fotos para as crianças, das mulheres negras de Vila Bela da Santíssima Trindade e afro-bolivianas. Então é um trabalho do fotógrafo Mário Friedlander, de Cuiabá, que é um fotógrafo premiado internacionalmente, faz fotos maravilhosas! Então eu procuro me inteirar, não só com a cultura de MT, com as pessoas que trabalham com a cultura, mas eu procuro também me envolver com a universidade. Quando eu vou num evento eu procuro trazer assim uma motivação para minha sala de aula. Eu procuro buscar esses parceiros (RIBEIRO, 2012a).

Podemos dizer que o contexto sociocultural exerce uma influência importante no trabalho da professora Sueli Ribeiro, uma vez que ela participa de atividades culturais na cidade, dialoga e estabelece parcerias com artistas e com professores da universidade. Um resultado similar foi encontrado por Faria et al. (2010), que destaca que, nos casos dos professores inovadores, o enriquecimento propiciado pela vida cultural (como poesias, músicas, literatura, teatro) é um fator diferenciador para pensar as elaborações metodológicas distintas da cultura tradicional da EF. Segundo os autores, este resultado reforça a ideia de que não é possível desvincular a trajetória pessoal dos professores da sua prática pedagógica.

\section{Princípios metodológicos do trabalho pedagógico}

Sobre os princípios metodológicos do seu trabalho com a dança, Sueli diz que:

Eu vou do princípio que a criança já tem algo em comum com a dança, da sua vivência, do seu bairro, do seu contato com a família, do seu contato com as festas religiosas, que aqui em Mato Grosso são muito comuns. A criança demonstra o conhecimento que ela tem da dança afro, então a partir daí que eu vou transmitir, demonstrar, ensinar outro conhecimento mais específico, ou mais científico sobre a 
dança. Se estamos trabalhando a dança afro, quando pergunto se ela tem conhecimento de dança afro, eu deixo ela demostrar o que sabe. Que movimento é esse, mesmo que esteja errado, eu dou essa oportunidade para que ela possa demonstrar. Então damos outros encaminhamentos, como: pesquisas, diálogos, estudo de campo, buscamos construir um novo conhecimento. Trabalhando o conteúdo contextualizado quanto a sua origem e significado, consequentemente permitirá que a criança observe e identifique a sua verdadeira identidade (RIBEIRO, 2012a).

Do ponto de vista metodológico, o confronto do saber popular (senso comum) com o conhecimento científico selecionado pela escola (saber escolar) é fundamental para a reflexão pedagógica, porque instiga o aluno a ultrapassar o senso comum e construir formas mais elaboradas de pensamento (COLETIVO DE AUTORES, 1992). Podemos identificar esta intencionalidade no trabalho pedagógico declarado pela professora.

Sueli também destacou que ela sempre inicia seu trabalho abordando as danças da cultura e dança local/regional. No aniversário de Cuiabá, ela prioriza e sensibiliza as crianças para as danças regionais, como o cururu ${ }^{1}$, o siriri ${ }^{2}$ e o rasqueado ${ }^{3}$. Além disto, ela percebe uma inter-relação das danças mato-grossenses com as culturas afro/indígena: "porque nós sabemos que a miscigenação da população cuiabana é branca e fortemente indígena e negra" (RIBEIRO, 2012a).

A professora relatou que muitas vezes as próprias crianças constroem a coreografia, ela divide grupos e os estudantes demonstram os movimentos que já sabem, ou criam movimentos novos e ela só vai enriquecendo. De acordo com Gariba e Franzoni (2007), buscar uma prática mais coerente através da dança consiste em possibilitar aos alunos expressaremse criativamente, sem exclusões, tornando essa linguagem corporal transformadora e não reprodutora. Já a abordagem crítico-superadora entende que "o ensino da EF também tem um sentido lúdico que busca instigar a criatividade humana à adoção de uma postura produtiva e criadora de cultura" (COLETIVO DE AUTORES, 1992, p. 40). É possível perceber esta intenção na forma em que a professora organiza seu trabalho pedagógico.

Além disto, a professora Sueli destaca a influência da identidade cultural no ritmo e corporeidade das crianças nos seus depoimentos:

Porque (...) nós trazemos o ritmo e o movimento, nós somos o povo negro, o índio, ele é riquíssimo na questão da corporeidade. Então é comum ver algum movimento da capoeira nas crianças, movimento do maculelê, do siriri, do rasqueado. Então o professor, a partir do momento que ele valoriza esse movimento, (...) junto com a criança, ele consegue construir (RIBEIRO, 2012a).

A professora entende que é necessário trabalhar a questão da autoestima do negro e do índio, uma vez que o branco faz parte da cultura dominante. Assim, segundo ela, é preciso valorizar as influências culturais afro-brasileiras e indígenas e fazer com que a criança compreenda o contexto em que estão inseridas.

\footnotetext{
${ }^{1}$ Roda de desafio cantado e de dança só para homens, com acompanhamento da viola de cocho e do ganzá. É uma das manifestações culturais mais autênticas nas festas religiosas e populares da região da baixada cuiabana. Uma das possíveis origens é a cerimônia funeral dos índios bororos. (PINHO, 2010).

${ }^{2}$ Dança tradicional mato-grossense, sua origem mescla influências afro-indígena-brancas. O ritmo é alegre, com muito movimento e variações de coreografias e toadas. Os instrumentos musicais são a viola de cocho, o ganzá, o mocho ou tamboril (PINHO, 2010).

${ }^{3}$ É uma dança regional das cidades ribeirinhas da bacia do rio Paraguai, muito presente na cultura popular cuiabana. Recebeu influência do siriri mato-grossense e da polca paraguaia, quando prisioneiros paraguaios ficaram confinados na margem direita do rio Cuiabá (hoje Várzea Grande-MT), durante a Guerra do Paraguai (PINHO, 2010).
} 
Então a escola tem que procurar dar possibilidade para que a criança se sinta neste contexto escolar. Que ao trabalhar uma cultura afro, ela vai estar trabalhando o que ela já tem da sua corporeidade, o que ela viu numa festa num determinado lugar aonde está o seu povo, a sua gente. Não a escola reproduzir o que ela viu no jornal ou viu na televisão, porque isto ela já tem de sobra, que a mídia faz isto muito bem. Então o nosso papel é praticamente reverter isso que colocam para as crianças de verdadeiro, de bonito, muitas vezes se ela se sente tão inferior, por que ela vai demonstrar um passo de dança afro? Por que ela vai dançar se ela não vê isso no jornal e na televisão? Então a escola tem uma obrigação, nós temos um dever a cumprir (RIBEIRO, 2012a).

De acordo com Giroux (1983), os conhecimentos das camadas desprivilegiadas economicamente, dos afrodescendentes ou de muitos outros grupos, quando emergem na escola, contestam o ponto de vista dominante e dão importância e oportunidade para vozes divergentes. Além disto, valorizar a cultura popular e, em especial, as danças que têm raízes nas culturas afro e indígenas pode ter um impacto positivo sobre a identidade e autoestima dos alunos. Bins e Molina Neto (2017) investigaram um professor de EF que tem uma experiência positiva no trato das questões étnicas. Além dos conteúdos da cultura negra ou indígena, o diferencial da prática deste professor é que ele estrutura suas aulas pautado em valores civilizatórios. Os autores constataram que, no início do ano escolar, poucos alunos deste professor se autodeclaravam negros, ao final do trabalho e das atividades desenvolvidas em classe, muitos alunos se declararam negros, o que demonstra o impacto positivo de se abordarem as questões étnicas e raciais nas aulas de EF.

Sueli relatou que a cada ano tenta inovar e buscar algo importante que signifique o seu trabalho. As datas comemorativas são uma motivação para o seu projeto com a dança. Como veremos adiante, no trabalho desenvolvido por Sueli, não se trata apenas de desenvolver coreografias para as festas, mas existe uma série de atividades de contextualização das danças. Conforme Brasileiro (2008), hoje é cada dia mais evidente a presença da dança nas escolas, em especial nos momentos festivos.

\section{O projetos pedagógico "Beleza tem raízes" e seus sub-projetos}

De acordo com as informações consultadas no projeto "Beleza tem raízes", ele surgiu da necessidade de desconstruir as atitudes racistas e preconceituosas na escola, e com o intuito de fortalecer as raízes do povo negro e a autoestima das crianças. Ele está vinculado ao Projeto Político Pedagógico (PPP) da escola, que tem como princípio a valorização da diversidade cultural, e contempla a questão da igualdade racial, de gênero, o respeito às diferenças.

Segundo a professora, no início do ano são escolhidos novos temas para o projeto junto com a comunidade escolar. As ações iniciam-se nas aulas de EF, mas depois se desenvolvem de forma interdisciplinar. Além disso, é escolhida uma nova turma para participar do projeto no início do ano letivo, mas o mesmo é aberto para outros alunos. Os participantes são considerados multiplicadores do conhecimento na comunidade escolar.

O envolvimento da EF com o PPP da escola também é um dos princípios pedagógicos da perspectiva crítico-superadora. Embora o projeto analisado seja extracurricular, ele faz parte do trabalho pedagógico desenvolvido na escola e, deste modo, também precisa estar articulado ao PPP da escola. Além disso, é importante que as ações sejam desenvolvidas de forma interdisciplinar. Nesse sentido, a pedagogia crítico-superadora defende que "é o tratamento articulado do conhecimento sistematizado nas diferentes áreas que permite ao aluno constatar, interpretar, compreender e explicar a realidade social complexa" (COLETIVO DE AUTORES, 1992, p. 28).

Em 2009, foi desenvolvido o subprojeto "A dança do chorado". A beleza desta dança despertou a curiosidade das crianças em querer saber como as garrafas se equilibram nas ca- 
beças das dançarinas. Esta é um dança afro de Vila Bela da Santíssima Trindade-MT. Ela surgiu no período colonial quando escravos fugitivos ou transgressores eram aprisionados e castigados. Nestes momentos, seus entes solicitavam o perdão e a liberdade dos prisioneiros, dançando o chorado. As mulheres cantam um tema próprio e dançam equilibrando uma garrafa na cabeça, para mostrar que apesar da festança, ninguém está embriagado (PINHO, 2010).

Este foi um dos trabalho premiados na categoria projetos pedagógicos, no " 6 Prêmio Construindo a Igualdade de Gênero". Neste subprojeto foram desenvolvidas as seguintes ações: diagnóstico do conhecimento dos/as estudantes sobre a dança do chorado e seus significados; questionamentos e demonstrações sobre os movimentos e melodias da dança; vídeo sobre a dança; desenhos e exercícios sobre os movimentos da dança; nas aulas de informática, pesquisas sobre a dança, aspectos históricos e culturais, com a elaboração de história em quadrinho; trabalhos de leitura e interpretação de textos sobre a cultura africana e afro-brasileira; nas aulas de física, geografia e artes, estudos sobre o equilíbrio, os espaços geográficos, culturais e artísticos; aula de campo em locais da cultura afro-brasileira no estado; apresentações para a comunidade escolar; palestras com integrantes de grupos de consciência negra; formação de grupos de dança do chorado; encontros.

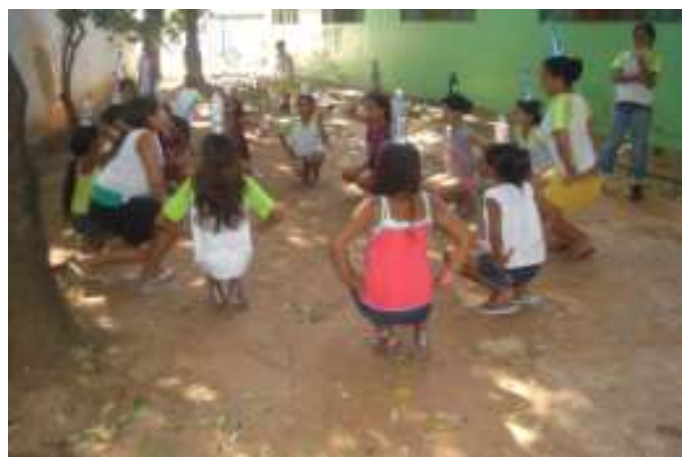

Figura 1 - Meninas dançando o chorado na escola

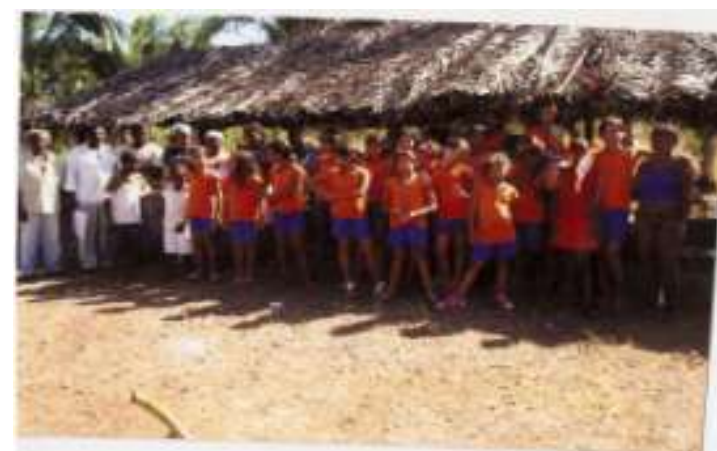

Figura 2 - Aula de campo em uma comunidade quilombola em Vila Bela da Santíssima Trindade-MT.

Fonte: Projeto Beleza tem raízes (RIBEIRO, 2012b).

Neira (2007) destaca a necessidade de o professor não ser um visitante na cultura popular, mas de pesquisar e aprofundar-se nos conteúdos da prática cultural tematizada, para melhor conduzir sua ação educativa. Além disso, no âmbito do multiculturalismo, alunos e professores assumem uma postura ativa de investigação in loco e com os representantes da comunidade, tal como a professora Sueli procura fazer com seus alunos, através das aulas de campo, pesquisas e vivências relacionadas à cultura e à dança estudada no projeto.

Em 2010, os estudantes questionaram por que não se toca rasqueado nas rádios cuiabanas. A partir desta pergunta foi desenvolvido o subprojeto "Nossos mestres do rasqueado, nossa herança musical", com o objetivo de propiciar um momento de conscientização, relembrando os mestres do rasqueado cuiabano e suas músicas. As ações deste subprojeto foram: identificação dos mestres do rasqueado, de suas obras e as contribuições para a música cuiabana; apresentações de cantos e coreografias de danças; entrevistas com amigos, familiares e moradores dos bairros onde os mestres nasceram; leitura, análise e interpretação de suas obras através de livros, documentos, fotografias; exposição dos trabalhos para a comunidade escolar; visita à rádio Cultura de Cuiabá e participação ao vivo na programação; apresentações de rasqueado na escola com a participação de artistas locais.

Deste modo, podemos perceber a importância que é dada à historicidade no trabalho pedagógico desenvolvido pela professora. Conforme o Coletivo de Autores (1992), é fundamental o desenvolvimento da noção de historicidade da cultura corporal na prática pedagógica 
e no ensino da EF, com o objetivo de compreender que a produção humana é histórica, inesgotável e provisória.



Figura 3 - Apresentações de artistas e músicos regionais. Fonte: Projeto Beleza tem raízes (RIBEIRO, 2012b).

No início de 2011, a escola levantou informações sobre a realidade dos alunos para a definição do tema anual do PPP da escola. As questões se relacionavam com: identidade, igualdade, valores, bairro, cidade, escola, comunicação, gênero, cultura e internet. Em seguida foi elaborado e desenvolvido o subprojeto "Mulheres do bairro Alvorada, mulher pantaneira". A escola procurou identificar quais eram as mulheres de representatividade no bairro da escola. Os alunos dos $5^{\circ}$ e $6^{\circ}$ anos realizaram uma pesquisa de campo que constatou que a maioria das mulheres do bairro é negra, que elas lutaram contra políticos e policiais na década de 70 pela ocupação e posse de suas terras, assegurando seus direitos de moradia e cidadania. Para homenageá-las, no dia das mulheres a escola organizou uma exposição de fotografias em preto e branco, que foi muito apreciada pela comunidade.



Figura 4 - Exposição "Mulheres do bairro" na escola.

Fonte: Projeto Beleza tem raízes (RIBEIRO, 2012b).

Para o Coletivo de Autores (1992), os temas da cultura corporal estão interrelacionados com os grandes problemas sócio-políticos atuais, como: ecologia, papéis sexuais, saúde pública, relações sociais do trabalho, preconceitos raciais, da deficiência, da velhice, distribuição do solo urbano e de renda etc. A reflexão sobre estes temas é necessária para possibilitar aos alunos entender a realidade social interpretando-a a partir de seus interesses de classe. Segundo McLaren (2001), os professores empoderados se tornam pesquisadores e ensinam aos seus alunos métodos de investigação, aprofundando seus poderes de pesquisa e análise e usando de forma mais efetiva as observações, as entrevistas, as fotografias, as filmagens, as anotações, as coletas de histórias.

Na ocasião da mostra, houve uma reflexão sobre as lutas e as conquistas das mulheres em MT. Foi mencionada a história da camponesa Laurinda de Lacerda Cintra, conhecida como Doninha do Tanque Novo, no município de Poconé-MT. Para conhecer os contos populares e histórias sobre esta mulher, um grupo de alunos, pais e professores da escola participa- 
ram de uma aula de campo em Poconé-MT, no dia 19 de março de 2011. Lá, o grupo da escola assistiu à dança dos mascarados, que é originária de uma mistura da contradança europeia, das danças indígenas e de ritmos negros, com várias evoluções coreográficas. Somente homens participam e eles vestem trajes masculinos e femininos, usam máscaras e chapéus com plumas, espelhos e outros adornos (PINHO, 2010).


Figura 5 - Dança dos mascarados em Poconé-MT. Figura 6 - Alunos da escola com os dançarinos mascarados ao fundo.

Fonte: Projeto Beleza tem raízes (RIBEIRO, 2012b).

A esse respeito, Neira (2007) destaca que é preciso compreender a escola como espaço de luta pela validação de significados culturais, através do confronto entre a cultura escolar e a cultura popular. Uma vez que o universo cultural e identitário de crianças pertencentes aos grupos socialmente desfavorecidos é praticamente o ambiente familiar e local, pode-se afirmar que sua entrada na escola implica num intenso embate de culturas. Por isto, McLaren (1997) defende uma postura multicultural da escola pela inserção dos conhecimentos populares no currículo, como, por exemplo, a tematização das práticas lúdicas familiares, das histórias orais, das biografias, das narrativas do povo, buscando a reconfiguração do conhecimento oficial.

Um bom ensino, na perspectiva do multiculturalismo, é aquele que considera seriamente a vida dos alunos, abrindo espaços para a diversidade de etnias, classes sociais, gêneros das populações estudantis. É importante que os educadores investiguem e recuperem as experiências dos estudantes, analisando seus saberes, suas práticas culturais e as formas pelas quais suas identidades se inter-relacionam com essas manifestações. $\mathrm{O}$ multiculturalismo insiste que os professores desenvolvam essas experiências de tal maneira que sejam respeitadas por toda a coletividade (NEIRA, 2007).

Com base nestas considerações e na análise das informações apresentadas, identificamos que o trabalho pedagógico da professora Sueli, no âmbito do projeto "Beleza tem raízes", se apoia na pedagogia crítico-superadora e no multiculturalismo. Além disso, sua abordagem da dança sempre ocorre através de projetos temáticos. Segundo Faria et al. (2010), uma característica dos professores inovadores no âmbito da educação física é a organização de conteúdos por meio de projetos temáticos, bimestrais ou semestrais. Embora nosso estudo não se debruce sobre a prática pedagógica na educação física, mas sim sobre o trabalho pedagógico em um projeto extracurricular, é interessante notar esta característica em comum.

\section{Considerações finais}

O objetivo deste trabalho foi compreender o ensino da cultura e das danças regionais mato-grossenses em um projeto pedagógico denominado "Beleza tem raízes", bem como identificar a história de vida, de formação e de atuação profissional da professora responsável por desenvolver este projeto. 
Através da análise das informações, pudemos identificar alguns elementos da sua história de vida, a influência familiar de seu pai, que era jogador de futebol, a sua experiência esportiva e cultural, a ausência da dança no seu período escolar e na faculdade, a migração para Cuiabá depois de formada. Também identificamos os princípios metodológicos no trabalho com a dança, e que a professora aprendeu a trabalhar com a dança na escola quando estava num curso de especialização. Nós também demos ênfase aos subprojetos anuais, seus objetivos e atividades desenvolvidas. As danças regionais tratadas nos subprojetos foram: siriri, cururu, rasqueado, chorado e dança dos mascarados. No projeto em questão, a professora utilizou várias estratégias metodológicas, trabalhou de forma interdisciplinar e integrada ao PPP da escola, e seu trabalho pedagógico fundamenta-se nas perspectivas crítico-superadora e multicultural.

Vale ressaltar que a professora destacou na entrevista que sua identidade étnica/racial de negra é bem definida. Nós pressupomos que este parecer ter sido um fator importante para o seu desenvolvimento profissional, principalmente no que tange ao trato pedagógico da dança e da cultura, uma vez que ela dá uma atenção especial para as manifestações culturais do povo negro e índio em sua prática pedagógica no projeto em estudo. Além disto, essa professora entende que é preciso valorizar as culturas afro-brasileira e indígena, uma vez que o branco faz parte da cultura dominante. Suas experiências culturais e a busca de parcerias estimulam e enriquecem seu trabalho pedagógico. Ela busca inovar seu trabalho a cada ano, diz que gosta do que faz e considera que, por isto, todos os momentos em sua carreira são significativos.

Nosso trabalho colocou em evidência uma dimensão do trabalho pedagógico de uma professora de EF, através da análise do projeto que tem como conteúdo principal as danças e a cultura popular do estado de Mato Grosso. Os resultados não podem ser generalizados, pois se trata de um estudo de caso, de uma professora particular, com uma determinada história de vida e de formação, sendo que sua atuação profissional é idiossincrática. Ainda assim, entendemos que os resultados merecem ser divulgados e quiçá possam inspirar outros trabalhos e projetos pedagógicos baseados numa perspectiva crítica e multicultural que valorizem a dança e as manifestações da cultura popular.

Uma contribuição importante deste estudo é dar visibilidade às experiências pedagógicas com a dança, ancoradas nas perspectivas críticas de educação, especialmente na perspectiva crítico-superadora e no multiculturalismo. Além disso, nós estimamos que o trabalho desenvolvido pela professora Sueli seja inovador no âmbito pedagógico, pois mesmo sendo um projeto extracurricular, suas ações estavam vinculadas ao PPP da escola, ela envolveu outras disciplinas e professores em um trabalho interdisciplinar, diversificou as estratégias metodológicas e proporcionou um ensino da dança de forma contextualizada e crítica. O ensino da cultura e danças regionais pela professora e seu enfoque origens e significados das danças contribuíram para valorizar a riqueza das manifestações culturais populares do estado de Mato Grosso, tal qual sugere o título do seu projeto: "Beleza tem raízes"!

\section{Referências}

ALVES, M. S. et al. O ensino da dança no Ensino Fundamental II e no Ensino Médio da Rede Estadual de Recife. Pensar a Prática, Goiânia, v. 18, n. 2, p. 350-366, abr./jun. 2015.

ALVES-MAZZOTI, A. J. Usos e abusos dos estudos de caso. Cadernos de Pesquisa, Campinas, v. 36, n. 129, p. 637-651, set./dez. 2006. 
ANDRÉ, M. E. D. A. Estudo de caso: seu potencial na educação. Cadernos de Pesquisa, Campinas, n. 49, p. 51-54, maio 1984.

BETTI, I. C. Rangel; BETTI, M. Novas perspectivas na formação profissional em Educação Física. Motriz, Rio Claro, v. 2, n. 1, p. 10-15, jun. 1996.

BINS, G. N.; MOLINA NETO, V. Mojuodara: uma possibilidade de trabalho com as questões étnico-raciais na educação física. Revista Brasileira de Ciências do Esporte, Porto Alegre, v. 39, n. 3, p. 247-253, maio 2017.

BOGDAN, R; BIKLEN, S. Investigação qualitativa na educação. Porto: Porto editora, 1994.

BUOGO, E. C. B.; LARA, L. M. Análise da dança como conteúdo estruturante da educação física nas Diretrizes Curriculares da Educação Básica do Paraná. Revista Brasileira de Ciências do Esporte, Florianópolis, v. 33, n. 4, p. 873-888, out./dez. 2011.

BRASILEIRO, L. T. O conhecimento no curricular escolar: o conteúdo dança em aulas de Educação Física numa perspectiva crítica. Movimento, Porto Alegre, v. 8, n. 3, p. 5-18, set./dez. 2002.

O ensino da dança na Educação Física: formação e intervenção pedagógica em discussão. Motriz, Rio Claro, v. 14, n. 4, p. 519-528, out./dez. 2008.

COLETIVO DE AUTORES. Metodologia do ensino da educação física. São Paulo: Cortez, 1992.

DINIZ, I. K. dos S.; DARIDO, S. C. Blog educacional e o ensino das danças folclóricas nas aulas de educação física: aproximações a partir do currículo do estado de São Paulo. Movimento, Porto Alegre, v. 21, n. 3, p. 701-716, jul./out. 2015.

FARIA, B. de A. et al. Inovação pedagógica na educação física. O que aprender com práticas bem sucedidas? Ágora para la EF y el Deporte, Rioja, n. 12, v. 11, p. 11-28, 2010.

FIGUEIREDO, V. M. C. de. A dança, a escola e seus diferentes espaços e tempos. Dança, Salvador, v. 2, n. 2, p. 81-92, jul./dez. 2013.

GARIBA, C. M. S.; FRANZONI, A. Dança escolar: uma possibilidade na educação física. Movimento, Porto Alegre, v. 13, n. 2, p. 155-171, maio/ago. 2007.

GIROUX, H. Pedagogia radical. São Paulo: Cortez, 1983.

KLEINUBING, N. D.; SARAIVA, M. do C. Educação Física Escolar e dança: percepções de professores do Ensino Fundamental. Movimento, Porto Alegre, v. 15, n. 4, p. 193-214, out./dez. 2009.

KLEINUBING, N. D.; SARAIVA, M. do C.; FRANCISCHI, V. G. A dança no Ensino Médio: reflexões sobre estereótipos de gênero e de movimento. Journal of Physical Education, Maringá, v. 24, n. 1, p. 71-82, 2013. 
MARQUES, D. A. P.; SURDI, A. C.; KUNZ, E. "Projeto de dança Uniguaçu": tecendo experiências pedagógicas. Motrivivência, Florianópolis, ano XXV, n. 40, p. 153-167, jun. 2013.

MCLAREN, P. Multiculturalismo crítico. São Paulo: Cortez, 1997.

Pedagogia da utopia. Santa Cruz do Sul: EdUNISC, 2001.

NEIRA, M. G. Ensino de Educação Física. São Paulo: Thomson Learning, 2007.

A cultura corporal popular como conteúdo do currículo multicultural da Educação Física. Pensar a Prática, Goiânia, v. 11, n. 1, p. 81-89, jan./jul. 2008.

NÓVOA, A. Os professores e as histórias de vida. In: NÓVOA, A. (Org.). Vidas de professores. 2. ed. Porto: Porto Editora, LDA, 1995. p. 13-33.

PINHO, M. P. de. Remedeia co que tem. Cuiabá: Edição do autor, 2010.

RIBEIRO, S. de F. X. Sueli de Fátima Xavier Ribeiro: depoimento [abr. 2012]. Entrevistadores: Marcos Godol e Gutemberg Xavier. Gravado em meio magnético. Cuiabá: FAUC, 2012a. Entrevista concedida ao projeto de pesquisa Cultura e danças regionais na escola.

Relatório do projeto "Beleza tem raízes". Cuiabá: mimeo, 2012b.

STAKE. R. E. Case studies. In: DENZIN, N. K.; LINCOLN, Y. S. (Org.). Handbook of qualitative research. London: Sage, 2000. p. 435-454.

SBÓRQUIA, S. P.; NEIRA, M. G. As danças folclóricas e populares no currículo da Educação Física: possibilidades e desafios. Motrivivência, Florianópolis, ano XX, n. 31, p. 79-98, dez. 2008.

SHIBUKAWA, R. M. et al. Motivos da prática de dança de salão nas aulas de educação física escolar. Revista Brasileira de Educação Física e Esportes, São Paulo, v. 25, n. 1, p. 19-26, jan./mar. 2011.

SOUZA, N. C. P., HUNGER, D. A. C. F.; CARAMASCHI, S. O ensino da dança na escola na ótica dos professores de dança e de educação física. Revista Brasileira de Educação Física e Esportes, São Paulo, v. 28, n. 3, p. 505-520, jul./set. 2014.

STRAZZACAPPA, M. Dança na educação: discutindo questões básicas e polêmicas. Pensar a Prática, Goiânia, v. 6, p. 73-85, jun./jul. 2003.

Recebido em: 25/09/2017

Revisado em: 23/04/2018

Aprovado em: 21/05/2018

Endereço para correspondência:

beleni.grando@gmail.com

Beleni Salete Grando

Universidade Federal de Mato Grosso

Av. Fernando Corrêa da Costa, 2367 - Boa Esperança, Cuiabá - MT, 78060-900 